\title{
Analysis of the Manufactured Tolerances with the Three-Dimensional Method of Angular Chains of Dimensions Applied to a Cylinder Head of Car Engine
}

\author{
Aida Mezghani ${ }^{1,2}$, Alain Bellacicco ${ }^{2}$, Jamel Louati ${ }^{1}$, Alain Rivière ${ }^{2}$, Mohamed Haddar ${ }^{1}$ \\ ${ }^{1}$ Mechanics Modelling and Production Research Unit, ENIS, TUNISIA \\ ${ }^{2}$ Laboratoire d'Ingénierie des Structures Mécaniques et des Matériaux, SUPMECA Paris, FRANCE \\ E-mail:mezghani_aida@yahoo.fr \\ Received May 4, 2010; revised July 21, 2010; accepted August 16, 2010
}

\begin{abstract}
This paper proposes an analysis method of the manufactured tolerances applied to a cylinder head of car engine. This method allows to determine the manufacturing tolerances in the case of angular chains of dimensions and to check its correspondence with the functional tolerances. The objective of this work is to analyze two parameterized functions: the angular defect $\Delta \alpha$ and the projected length $\lg$ of the toleranced surface. The angular defects are determined from the precision of the machine tools, we consider only the geometrical defects (position and orientation of surfaces), making the assumption that the form defects are negligible. The manufactured defect is determined from these two parameterized functions. Then it will be compared with the functional condition in order to check if the selected machining range allows, at end of the manufacturing process, to give a suitable part.
\end{abstract}

Keywords: Three-Dimensional Tolerancing, Manufacturing Process, Toleranced Surface, Angular Defect.

\section{Introduction}

Today, the manufacturing engineers face the problem of selecting the appropriate manufacturing process (machining processes and production equipments) to ensure that design specifications are satisfied. Developing a suitable process is complicated and time-consuming.

To verify the capacity of a manufacturing process to make the corresponding parts it is necessary to simulate the defects that it generates and to analyze the correspondence of produced parts with the functional tolerances. In order to check the capability of a manufacturing process to carry out suitable parts, it is necessary to analyze each functional tolerance. In the literature available on this subject, the evaluation of a process in terms of functional tolerances is called the tolerance analysis, [1-5].

The best way to analyze the tolerances is to simulate the influence of parts deviations on the geometrical requirements. Usually, these geometrical requirements limit the gaps or the displacements between product surfaces. For this type of geometrical requirements, the influences of parts deviations can be analyzed by different ap- proaches as Variational geometry [6,7], Vectorial tolerancing [8,9], Clearance space and deviation space [1013], Gap space [14], quantifier approach [15,16], kinematic models [17,18], Inertial Tolerancing [19].

In this paper the three-dimensional method of angular chains of dimensions is used for simulating the manufacturing process and then manufactured torerancing is determined to carry out tolerance analysis

\section{Description of the Method}

The three-dimensional method of angular chains of dimensions, initiated by [20], allows the optimization of the calculation of three-dimensional angular dispersions. This method also allows the validation of the manufacturing range by taking into account the processes precision.

The objective of this work is to analyze two parameterized functions: the angular defect $\Delta \alpha$ and the projected length $\lg$ of the toleranced surface. The angular defects are determined from the precision of the machine tools, only the geometrical defects are considered (position and orientation of surfaces), making the assumption 
that the form defects are negligible. The manufactured defect is first determined from these two parameterized functions. Then it is compared with the functional condition in order to check if the selected machining range allows, at the end of the manufacturing process, to give a suitable part.

\subsection{The Angular Defect}

The angular defect can be determined through two methods: the 2D method used currently in the industries and the new 3D method, in order to compare the results given by both methods.

\subsubsection{D Approach}

To determine the angular defect of a surface with the 2D method, it is necessary to choose two projection plans (perpendicular to the toleranced surface). Then the angular defect in each plan is determined by the 1D method of angular chains of dimensions. The angular defect of the toleranced surface is given by the combination of both angular defects found in the analysis plans.

If the angular chains of dimensions are made in two projection plans ( $\mathrm{H}$ and $\mathrm{V}$ for example), perpendicular between them, the defect in the plan $\mathrm{V}$ lies between zero and an angle $\Phi_{1}$. It will combine with a defect, manufactured in the plan $\mathrm{H}$, located between zero and $\Phi_{2}$.

The greatest angular defect $\Delta \alpha_{\max }$, resulting from the combination of the two defects, is given by:

$$
\Delta \alpha_{\max }=\sqrt{\Phi_{1}^{2}+\Phi_{2}^{2}}
$$

$\Delta \alpha_{\max }$ is located in the direction which forms an angle $\theta$ with the plan $\mathrm{V}$.

$$
\theta=\operatorname{Atan}\left(F_{2} / F_{1}\right)
$$

The diagram of the angular defects is shown in Figure 1.

Referring to this diagram, the angular defect $\Delta \alpha$ is given in each analysis direction in accordance with $\theta$. The value of the angular defect is equal to the length of the segment OA.

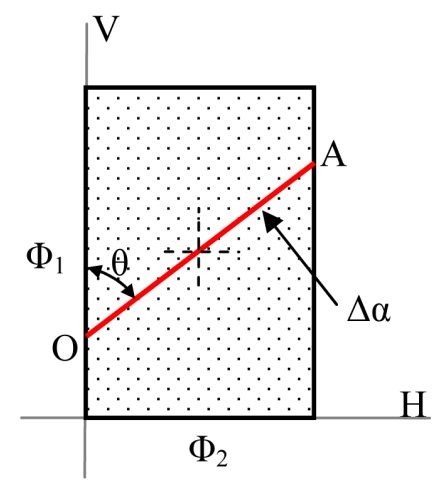

Figure 1. Diagram of the angular defects (2D method).

\subsubsection{D Approach}

In reality, the normal vectors $\vec{n}$, of the various machined surfaces, is contained in a volume forming a conical zone of tolerance. These zones of tolerance constitute solid angles.

The method consists in cumulating the solid angles which represent the angular defects of the part's surfaces in the aim of finding the angular defect of the toleranced surface.

For a given machining range, it is necessary to determine the locus of each manufactured defect, from the 1st phase until the nth phase. The combination of these defects gives a solid angle comparable to a right cone with an oblong form directrix. The manufactured defects diagram will have an oblong form instead of a rectangular one.

A parameterized diagram is drawn on a CATIA file related to a table of parameter setting. This parameter setting makes it possible to change the shape of the diagram according to the machine precision and the orientation of positioning surfaces (Figure 2).

Referring to this diagram, the angular defect $\Delta \alpha$ is given in each analysis direction in accordance with $\theta$. The value of the angular defect is equal to the length of the segment BC. To determine the value of $\Delta \alpha$ the CATIA macros are used. For each value of $\theta, \Delta \alpha$ is measured then transferred towards an EXCEL file.

\subsection{The Manufactured Defect}

The manufactured defect $\mathrm{tf}$ is the greatest height measured between the toleranced element, surface $\mathrm{S}$ considered plane, and the associated exact theoretical plan.

The measured defect $\mathrm{tf}$ is given by the Equation (3)

$$
\operatorname{tf}(\theta)=\Delta \alpha(\theta) \times \lg (\theta)
$$

with

$\Delta \alpha(\theta)$ : the angular defect of the toleranced surfaces in each analysis plan.

$\lg (\theta)$ : the projected length of the toleranced surface in each analysis plan.

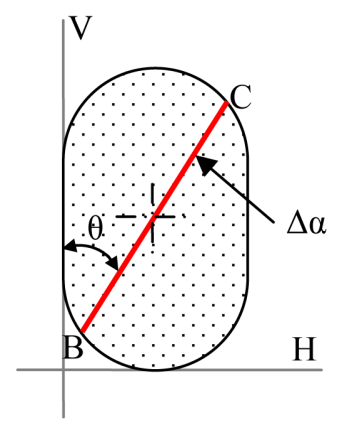

Figure 2. Diagram of the angular defects (3D method). 
When S surface has a particular form (Figure 3), the projected length $\mathrm{lg}$ is not uniform in all the analysis directions. To determine the various values of the projected length according to $\theta$ we use software CATIA. The values of $\mathrm{lg}$ are extracted from the CAD model of the part. The projected surface length is measured for each value of $\theta$ then automatically transferred from CATIA towards an Excel file. Then we obtain a table which contains all the values of $\lg$ for a sweeping of $\theta$.

The projected length and the angular defect $\Delta \alpha$ are given for a sweeping of $\theta$ then the manufactured defect tf can be deduced. tfmax will be compared with the functional condition.

\section{Case Study: A Cylinder Head of Car Engine}

In this paper, the studied example is a cylinder head of car engine. The functional geometrical conditions of orientation are checked by using the method of three-dimensional angular chains of dimensions.

The geometrical orientation conditions, such as parallelism, perpendicularity and angularity will be treated in order to check their respect according to the machining processes precision.

Figure 4 represents the Digital Mock-Up (DMU) of the cylinder head made with the geometrical orientation conditions to study.

Digital Mock Up or DMU allows real-time visualization of the complete product in 3 dimensions and to describe it during its life cycle. The DMU is a virtual version of the product that makes it possible to create all the

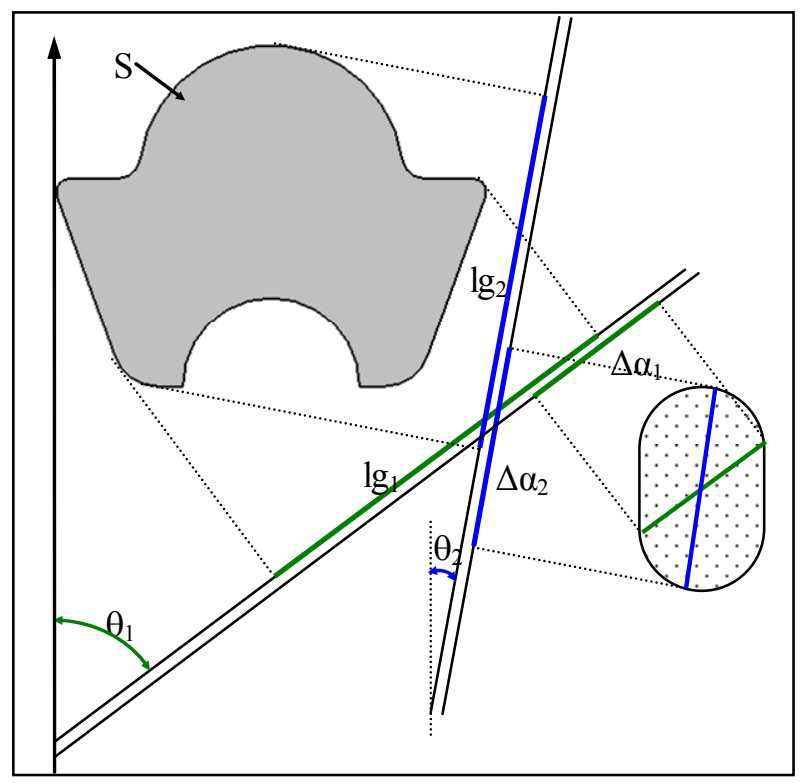

Figure 3. Case of particular form surface.

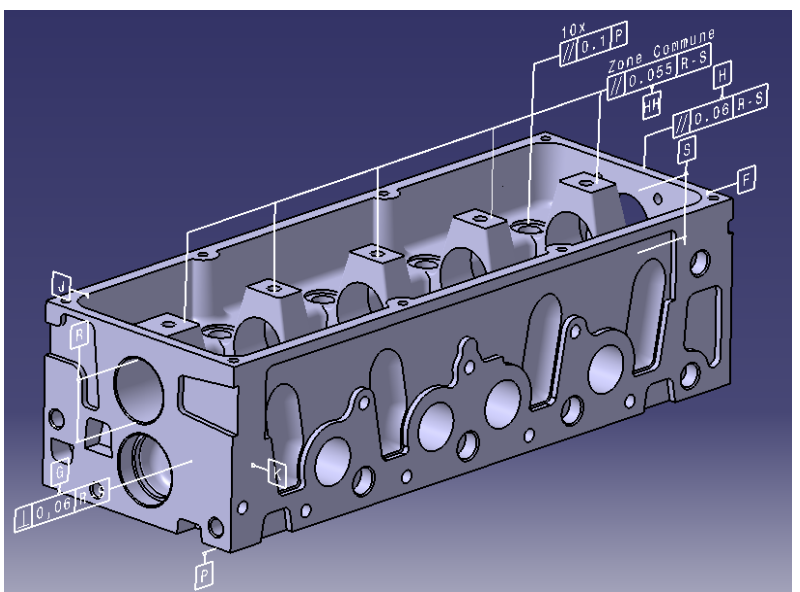

Figure 4. Digital Mock-Up (DMU) of the cylinder head with the orientation geometrical conditions.

simulations needed for product development, manufacturing and the aftermarket.

The DMU enables the simulation of the product with the intention of knowing future and to replace the physical prototypes with the virtual ones.

The cylinder head machining range comprises three phases. Table 1 summarizes them. This table highlights the manufactured and positioning surfaces in each phase.

We will study the feasibility of the DD condition: parallelism of $\mathrm{H}$ relative to R-S. The angular defect is determined by the $2 \mathrm{D}$ method then the $3 \mathrm{D}$ or the spatial method.

The precision of the used machine is $0.007 \mathrm{~mm}$. This corresponds to an angular defect $\Delta \alpha=0.07 \mathrm{mrd}$ for 100 $\mathrm{mm}$ length and in any direction.

Table 1. Machining range of the head cylinder.

\begin{tabular}{|c|c|c|c|c|}
\hline \multirow{2}{*}{$\begin{array}{l}\text { Operation } \\
\text { OP } 20\end{array}$} & \multicolumn{3}{|c|}{ Positioning surfaces } & \multirow{2}{*}{$\begin{array}{l}\begin{array}{l}\text { Machined } \\
\text { surfaces }\end{array} \\
\mathrm{P}\end{array}$} \\
\hline & W & $\mathrm{V}$ & $\mathrm{Y}$ & \\
\hline \multirow{4}{*}{ OP30 } & $\mathrm{P}$ & $\mathrm{V}$ & $\mathrm{Y}$ & $\mathrm{H}$ and $\mathrm{HH}$ \\
\hline & $\mathrm{P}$ & V & $F^{\prime}$ & $\mathrm{J}$ \\
\hline & $\mathrm{P}$ & $\mathrm{J}$ & $F^{\prime}$ & $\mathrm{K}$ \\
\hline & $\mathrm{P}$ & $\mathrm{K}$ & $\mathrm{Y}$ & $\mathrm{F}$ and $\mathrm{G}$ \\
\hline \multirow{4}{*}{ OP40 } & $\mathrm{P}$ & $\mathrm{K}$ & $\mathrm{F}$ & A-B \\
\hline & $\mathrm{P}$ & $\begin{array}{l}542 \\
\text { (cylindrical pins) }\end{array}$ & $\begin{array}{l}\text { A } \\
\text { (milled } \\
\text { pins) }\end{array}$ & $601-610$ \\
\hline & $\mathrm{P}$ & $\begin{array}{l}542 \\
\text { (cylindrical pins) }\end{array}$ & $\begin{array}{l}515 \\
\text { (milled } \\
\text { pins) }\end{array}$ & $\begin{array}{l}\text { Spot-facing } \\
601-610\end{array}$ \\
\hline & $\mathrm{P}$ & $\begin{array}{l}542 \\
\text { (cylindrical pins) }\end{array}$ & $\begin{array}{l}515 \\
\text { (milled } \\
\text { pins) }\end{array}$ & $\mathrm{R}-\mathrm{S}$ \\
\hline
\end{tabular}




\subsection{The Angular Defect}

\subsubsection{D Approach}

In order to determine the angular defect generated by the manufacturing process, in each projection plan, we use the $1 \mathrm{D}$ angular chains of dimensions.

The machining range proposed for the cylinder head manufacturing indicates that the toleranced surface is machined before the reference element, which explains the need for a tolerances transfer.

Figures 5 and $\mathbf{6}$ show the 1D dimensions chains plot on the projection plans (PL1 Parallel to G and F, PL2 Parallel to $\mathrm{K}$ and $\mathrm{J}$ ).

The cumulated defect in the projection plan can be deduced from this chain of dimensions:

- in PL1 the cumulated angular defect is $\Delta \alpha=0.14 \mathrm{mrd}$.

- in PL2 the cumulated angular defect is $\Delta \alpha=0.07 \mathrm{mrd}$.

Then the diagram of the angular defect is represented in Figure 7 with $\Phi_{1}=0.07 \mathrm{mrd}$ and $\Phi_{2}=0.14 \mathrm{mrd}$.

Referring to this diagram the angular defect $\Delta \alpha$ can be given in each analysis direction in accordance with $\theta$. The value of the angular defect is equal to the length of the segment OA. So we obtain the result of Figure 8 which represents the angular defect $\Delta \alpha$ in each analysis direction.

According to this result the maximum angular defect is $0.155 \mathrm{mrd}$. It's located in the analysis direction which has $\theta=1.11 \mathrm{rd}$

This result can be found using calculation since $\Delta \alpha_{\max }=\sqrt{\Phi_{1}^{2}+\Phi_{2}^{2}}=0.156 \mathrm{mrd}$.

\subsubsection{D Approach}

To determine the resulting angular defect, it's necessary to cumulate the solid angles and the plan angles which represent the angular defects of the manufactured surfaces.

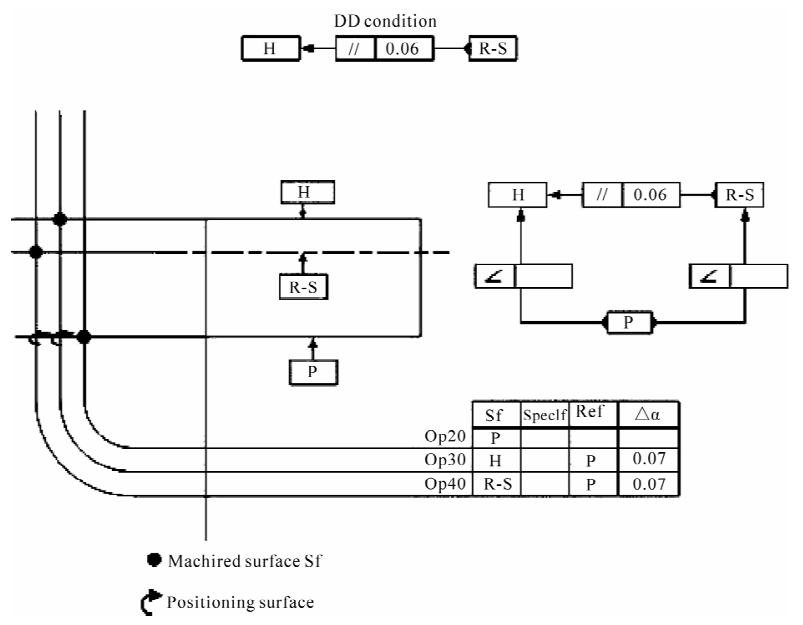

Figure 5. 1D angular dimensions chain in PL1.

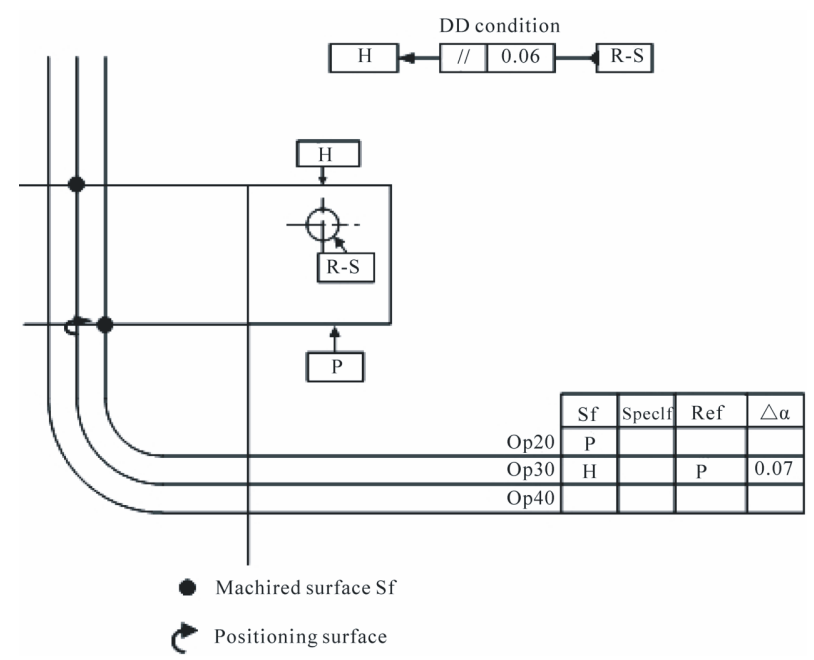

Figure 6. 1D angular dimensions chain in PL2.

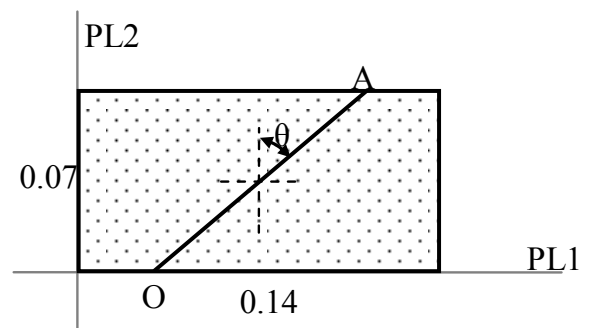

Figure 7. The angular defect diagram (2D Method).

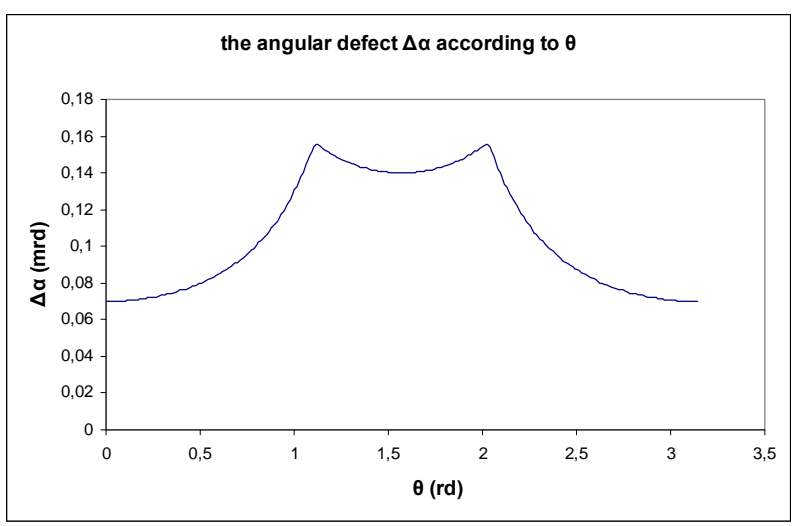

Figure 8. The angular defect of the toleranced surface according to $\theta$. (2D method).

The defect associated to the toleranced surface (normal vector $\vec{Z}$ ) is modeled by a solid angle which the directrix diameter depends of the precision of the machine. The direction vector for R-S is $\overrightarrow{\mathrm{x}}$, therefore only the angular defect of rotation according to $\vec{y}$ is considered. The angular defect of rotation according to $\vec{Z}$ does not have influence on the respect of the parallelism condition.

Table 2 summarizes the method of determination of the angular defects diagram. 
Table 2. Directrix of the cumulated defect.

\begin{tabular}{cccc}
\hline phase & $\begin{array}{c}\text { Manufactured } \\
\text { surface }\end{array}$ & $\begin{array}{c}\text { Locus of the } \\
\text { manufactured } \\
\text { defect }\end{array}$ & $\begin{array}{c}\text { Directrix of the } \\
\text { cumulated defect }\end{array}$ \\
\hline 30 & $H$ & Angle solide & \\
\hline & & \\
\hline
\end{tabular}

Figure 9 presents the diagram of the angular defect $\Delta \alpha$ given by the 3D method. The manufactured defects diagram has an oblong form instead of a rectangular form.

Referring to this diagram the angular defect $\Delta \alpha$ can be given in each analysis direction in accordance with $\theta$. The value of the angular defect is equal to the length of the segment BC. We obtain the result of Figure 10 which represents the angular defect $\Delta \alpha$ in each analysis direction.

The greatest defect is equal to $0.14 \mathrm{mrd}$. It's located in the analysis direction which has $\theta=1.57 \mathrm{rd}$. It is noticed that the angular defect determined by the $3 \mathrm{D}$ approach is smaller than the angular defect found by the 2D method. After that we will use the results of Figure 8 and Figure $\mathbf{1 0}$ to determine the manufactured tolerances in both cases and to compare them with the functional specifications.

\subsection{The Manufactured Defect}

The method requires geometrical data relative to the toleranced surface. These data are extracted from the CAD model of the cylinder head. Figure 11 represents the form of the toleranced surface.

We use CATIA to determine the projected length in each analysis direction that is shown in Figure12.

To determine the critical defect, it is necessary to express the measured defect tf according to the two independent variables: the angular defect $\Delta \alpha(\theta)$ and the projected length $\lg (\theta)$. Figure 13 and Figure 14 present the manufactured defect determined respectively by the $2 \mathrm{D}$ method and 3D method.

The result of Figure 13 shows that the maximum manufactured defect is equal to $0.067 \mathrm{~mm}$. It's exceeded the limits imposed by the functional requirement (parallelism of $0.06 \mathrm{~mm}$ according to R-S). So the used machine cannot satisfy the parallelism condition. We must use a more precise machine. This increases the production cost of the part.

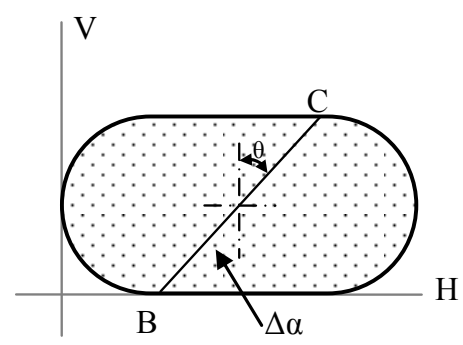

Figure 9. The angular defect diagram (3D Method).

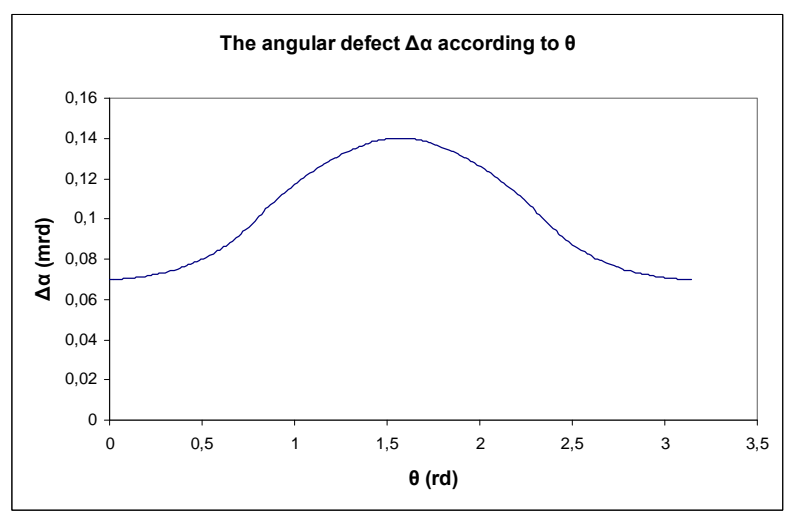

Figure 10. The angular defect of the toleranced surface according to $\theta$. (3D method)

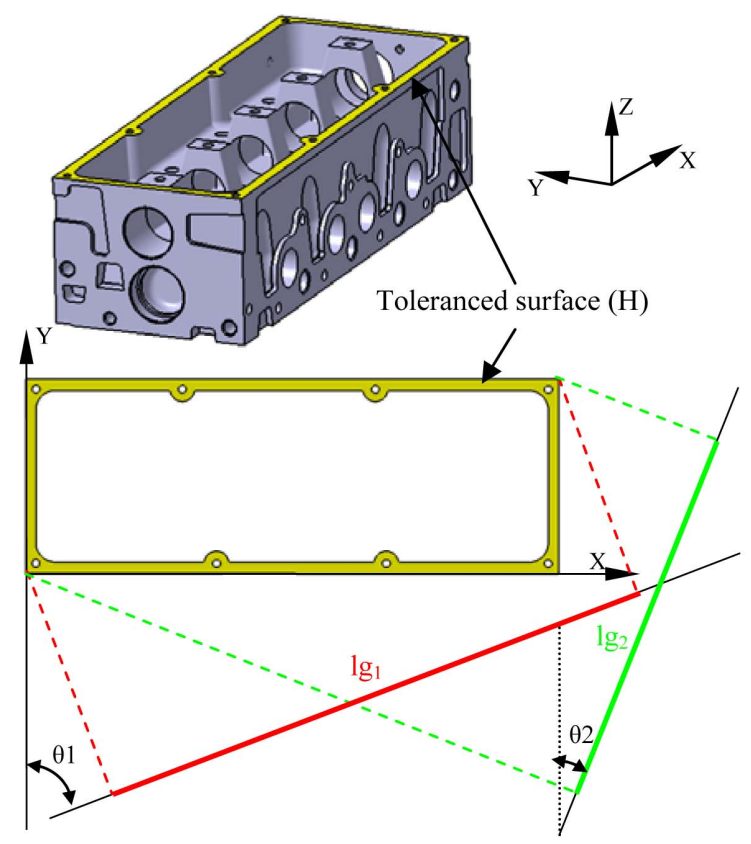

Figure 11. Form of the toleranced surface.

On the other hand, the result given by the 3D method shows that the maximum manufactured defect is equal to $0.058 \mathrm{~mm}$. The parallelism condition is checked. The use of a machine the precision of which is $0.007 \mathrm{~mm}$ makes it possible to satisfy the DD condition. 


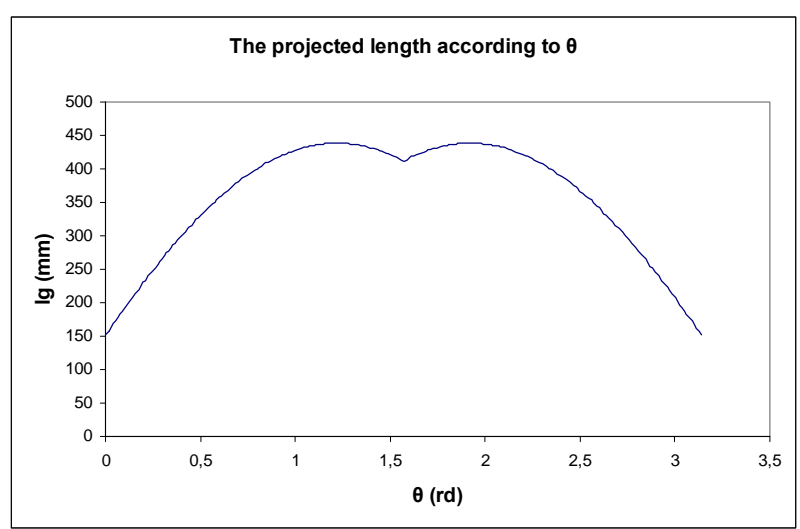

Figure 12. The projected length of the toleranced surface according to $\theta$.

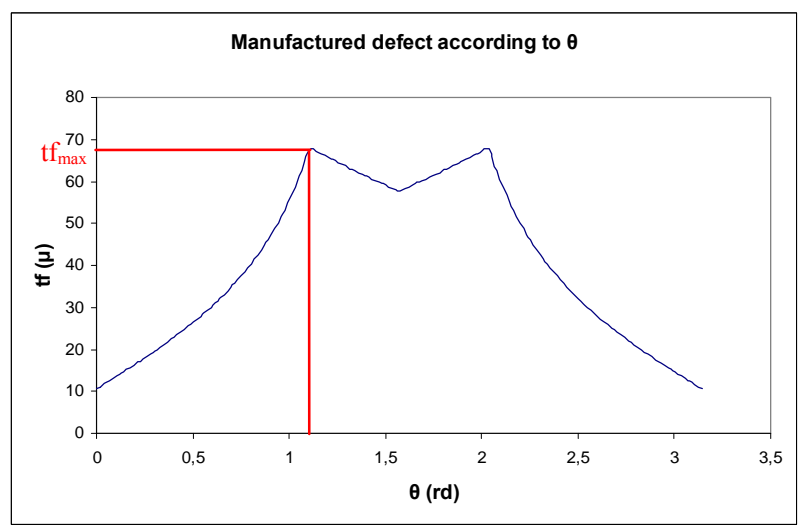

Figure 13. The manufactured defect of the toleranced surface (H) according to $\theta$ (2D method).

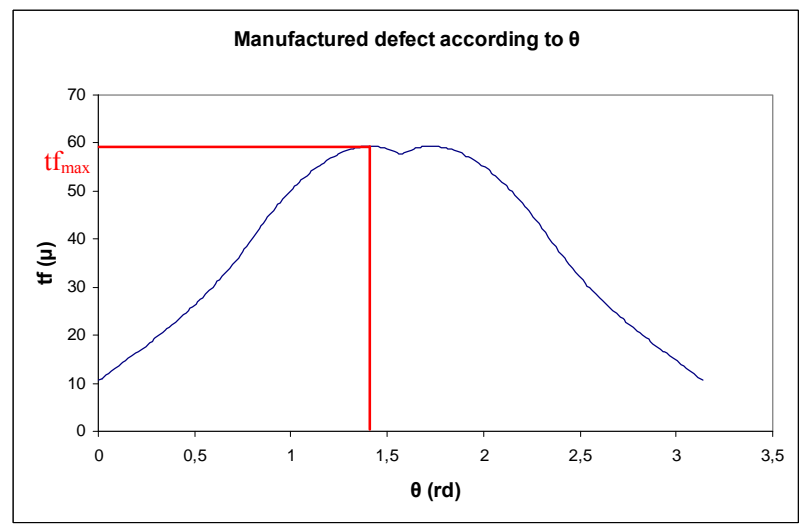

Figure 14. The manufactured defect of the toleranced surface $(\mathrm{H})$ according to $\theta$ (3D method).

The 3D method allows to optimize the manufactured tolerance intervals and to check the feasibility of the parts according to the machine precision. We will be able to choose a less precise machine and to reduce the production cost.

Next we present the results for several orientation con- ditions. The same methodology is used to check the correspondence of these conditions with the functional specifications according to the machine precision.

Condition 2: parallelism of R-S relative to datum surface $P$.

In this case the toleranced element is machined directly relative to the datum surface P. it doesn't need a tolerance transfer. At worst the manufactured tolerance must be equal to the value of the tolerance interval of the $\mathrm{DD}$ requirement $(0.04 \mathrm{~mm})$. The parametric function $\lg (\theta)$ is a constant equal to the length of the axis R-S. As a result, the precision machine needed to satisfy the functional specification is of $\mathrm{p}=0.097 \mathrm{~mm}$.

Condition 3: parallelism of $\mathrm{HH}$ relative to datum axis R-S.

Figure 15 and Figure 16 present the manufactured defect determined respectively by the 2D method and 3D method for $\mathrm{p}=0.007 \mathrm{~mm}$.

Both methods show that the use of a machine, which precision is $0.007 \mathrm{~mm}$, makes it possible to satisfy the functional specification (parallelism of $0.055 \mathrm{~mm}$ relative to R-S).

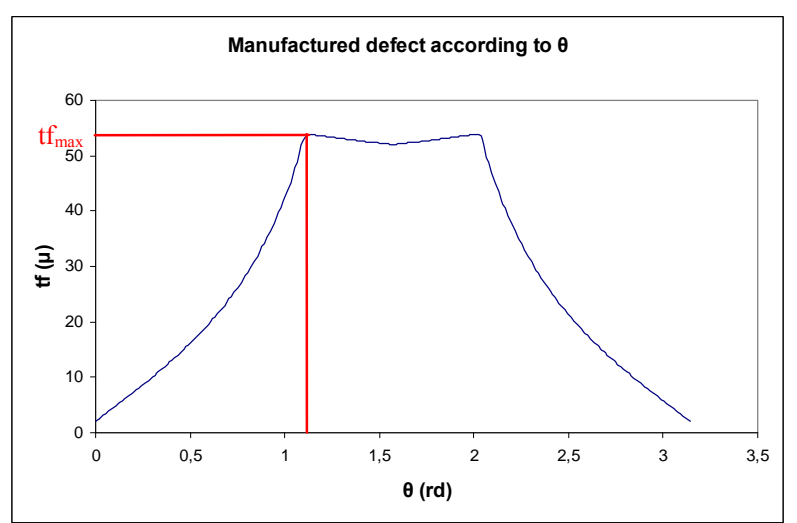

Figure 15. The manufactured defect of the toleranced surface according to $\theta$ (2D method).

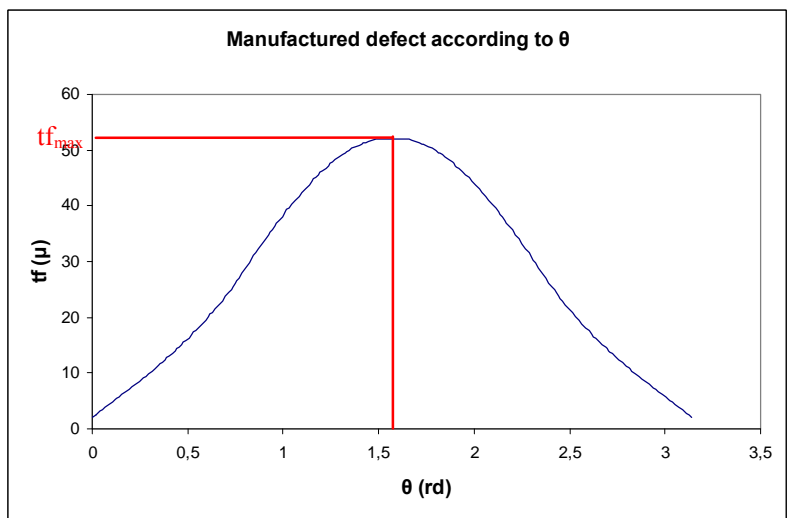

Figure 16. The manufactured defect of the toleranced surface according to $\theta$ (3D method). 
- 2D method: $\mathrm{tf}_{\max }=0.052 \mathrm{~mm}$

- 3D method: $\mathrm{tf}_{\max }=0.054 \mathrm{~mm}$

Condition 4: parallelism of the melts of spot facing relative to the datum surface $P$.

The toleranced element is machined directly relative to the datum surface. Only the defect generated by the machining of the toleranced element is considered. Consequently, the diagram of the angular defect determined by the $2 \mathrm{D}$ and $3 \mathrm{D}$ method has respectively a square form and a circular form.

The toleranced surface has a circular form, so $\lg (\theta)$ is constant and equal to the diameter of the surface, which explains the result of the Figure 18. The manufactured defect is a constant for any value of $\theta$.

Figure 17 and Figure 18 present the manufactured defect determined respectively by the $2 \mathrm{D}$ method and $3 \mathrm{D}$ method for $\mathrm{p}=0.45 \mathrm{~mm}$.

The DD condition is checked only with the $3 \mathrm{D}$ method. This method allows the optimization of the choice of the machine compared to the $2 \mathrm{D}$ method.

We notice that the precision $\mathrm{p}=0.45 \mathrm{~mm}$ is justified by tow facts:

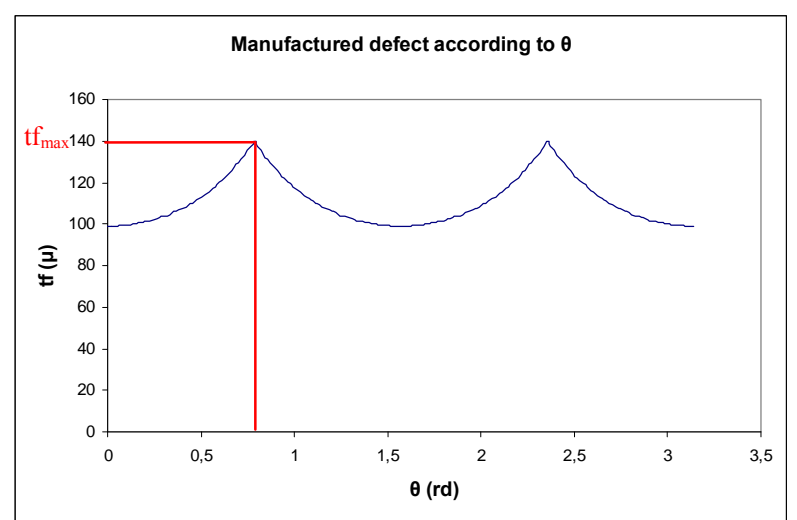

Figure 17. The manufactured defect of the toleranced surface according to $\theta$ (2D method).

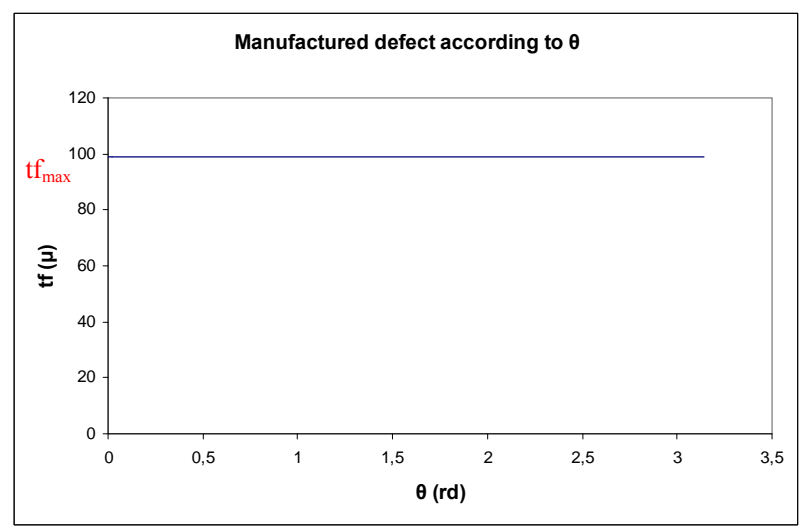

Figure 18. The manufactured defect of the toleranced surface according to $\theta$ (3D method).
- The dimensions of the toleranced surface are smaller than the dimensions of the other toleranced surfaces studied previously.

- The toleranced element is machined directly relative to the datum surface

Condition 5: perpendicularity of $\mathrm{G}$ relative to the datum axis R-S.

In the same way, the condition of perpendicularity is analyzed. Figure 19 and Figure 20 present the manufactured defect determined respectively by the $2 \mathrm{D}$ method and $3 \mathrm{D}$ method for $\mathrm{p}=0.01 \mathrm{~mm}$.

We find the following results:

- 2D method: $\mathrm{tf}_{\max }=0.052 \mathrm{~mm}$

- 3D method: $\mathrm{tf}_{\max }=0.037 \mathrm{~mm}$

The result find with the $3 \mathrm{D}$ method shows that the condition of perpendicularity of $\mathrm{G}$ relative to $\mathrm{R}-\mathrm{S}$ can be respected if $\mathrm{p}=0.01 \mathrm{~mm}$

It is noticed that dimensions of the toleranced surfaces have a great influence on the choice of the machine. It is always delicate to respect the tight tolerance interval relative to large-sized toleranced surfaces.

Table 3 summarizes the results find with the 3D method.

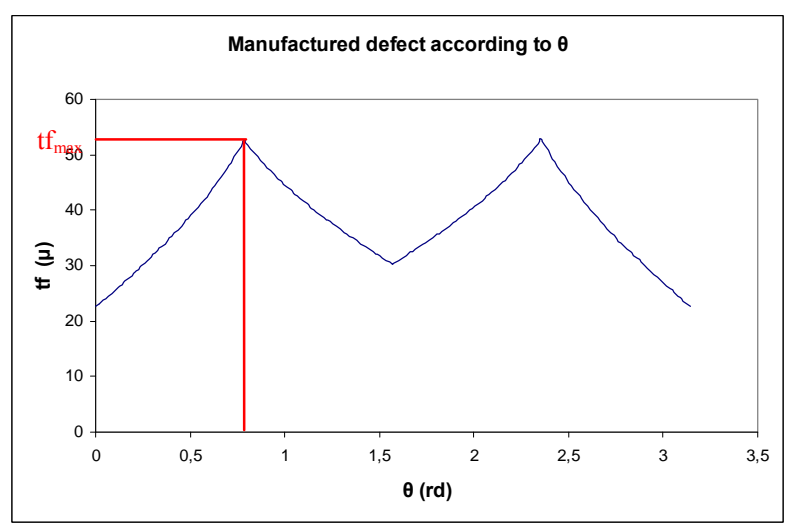

Figure 19. The manufactured defect of the toleranced surface according to $\theta$ (2D method).

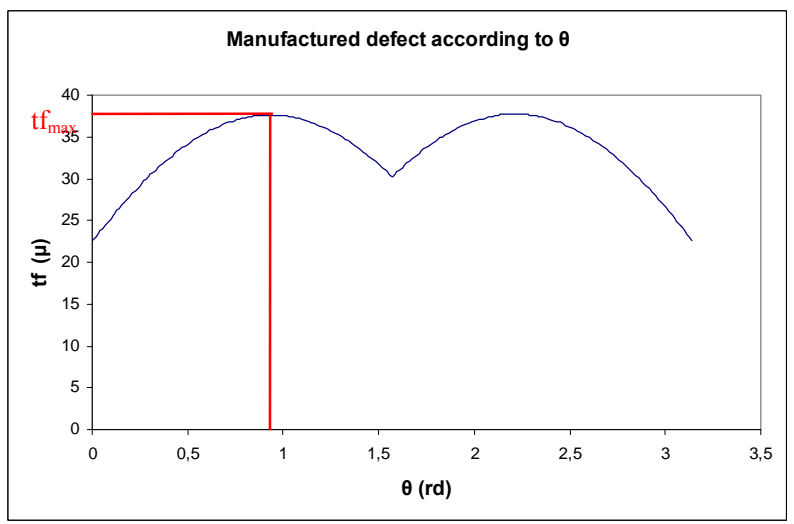

Figure 20. The manufactured defect of the toleranced surface according to $\theta$ (3D method). 
Table 3. Summary of the results.

\begin{tabular}{|c|c|c|c|c|c|c|}
\hline \multicolumn{4}{|c|}{ DD condition } & $\begin{array}{l}\text { Form and di- } \\
\text { mension of the } \\
\text { toleranced sur- } \\
\text { face }\end{array}$ & $\begin{array}{l}\text { Manufactured } \\
\text { defect find } \\
\text { with the 3D } \\
\text { method }\end{array}$ & $\begin{array}{l}\text { Machine } \\
\text { precision }\end{array}$ \\
\hline \multicolumn{4}{|c|}{ Condition 1} & \multirow{2}{*}{$\begin{array}{l}\text { Rectangular } \\
\text { form } \\
151 \times 411.5 \mathrm{~mm}\end{array}$} & \multirow{2}{*}{$\begin{array}{c}\mathrm{tf}_{\max }= \\
0.058 \\
\mathrm{~mm}\end{array}$} & \multirow{2}{*}{$\mathrm{p}=0.007 \mathrm{~mm}$} \\
\hline $\mathrm{H}$ & // & 0.06 & R-S & & & \\
\hline \multicolumn{4}{|c|}{ Condition 2} & \multirow{2}{*}{$\begin{array}{l}\text { Axis } \\
411.5 \mathrm{~mm}\end{array}$} & \multirow{2}{*}{$\begin{array}{r}\mathrm{tf}_{\max }=0.04 \\
\mathrm{~mm}\end{array}$} & \multirow{2}{*}{$\mathrm{p}=0.097 \mathrm{~mm}$} \\
\hline R-S & / & 0.0 & $\mathrm{P}$ & & & \\
\hline \multicolumn{4}{|c|}{ Condition 3} & \multirow{2}{*}{$\begin{array}{l}\text { Rectangular } \\
\text { form } \\
371.5 \times 27 \mathrm{~mm}\end{array}$} & \multirow{2}{*}{$\begin{aligned} & \mathrm{tf}_{\max }= 0.054 \\
& \mathrm{~mm}\end{aligned}$} & \multirow{2}{*}{$\mathrm{p}=0.007 \mathrm{~mm}$} \\
\hline $\mathrm{HH}$ & // & 0.055 & R-S & & & \\
\hline \multicolumn{4}{|c|}{$\begin{array}{l}\text { Condition } 4 \\
10 x\end{array}$} & \multirow{2}{*}{$\begin{array}{l}\text { Circular form } \\
\varnothing 22 \mathrm{~mm}\end{array}$} & \multirow{2}{*}{$\begin{aligned} & \mathrm{tf}_{\max }= 0.099 \\
& \mathrm{~mm}\end{aligned}$} & \multirow{2}{*}{$\mathrm{p}=0.45 \mathrm{~mm}$} \\
\hline / & 0 & & & & & \\
\hline \multicolumn{4}{|c|}{ Condition 5} & \multirow{2}{*}{$\begin{array}{l}\text { Rectangular } \\
\text { form } \\
150 \times 113 \mathrm{~mm}\end{array}$} & \multirow{2}{*}{$\begin{aligned} & \mathrm{tf}_{\max }= 0.037 \\
& \mathrm{~mm}\end{aligned}$} & \multirow{2}{*}{$\mathrm{p}=0.01 \mathrm{~mm}$} \\
\hline $\mathrm{G}$ & $\perp$ & 0.05 & R-S & & & \\
\hline
\end{tabular}

The machining of surfaces $\mathrm{H}$ and $\mathrm{HH}$ requires a more precise machine compared with the other part surfaces. That is explained by two reasons: on the one hand, the tolerance intervals of the functional specifications are too tight; on the other hand, the toleranced surfaces have larger dimensions. Moreover, in both cases, toleranced surfaces are not machined directly relative to the datum. Consequently the accumulation of the defects generated in each phase of the manufacturing range increases the manufactured defect.

\section{Conclusions}

In this paper, we have presented a three-dimensional method of manufactured tolerances analysis applied to a cylinder head of a car engine. This method makes it possible to evaluate the validity of a manufacturing process and to analyze the defects which occur in the various production phases. The use of CATIA macros decreases considerably the processing time of the examples and facilitates the treatment of the geometrical conditions.

We showed here an example of a cylinder head of a car engine in which we can see that the choice of the machine precision depends on the dimensions of the toleranced surfaces and the interval of tolerance required by the Design Department. This method is not a specific one, but a general one. It can be used in the case of industrial complex examples.

\section{References}

[1] F. Germain, D. Denimal and M. Giordano, "A Method for Three Dimensional Tolerance Analysis and Synthesis Applied to Complex and Precise Assemblies," in IFIP International Federation for Information Processing, Volume 260, Micro-Assembly Technologies and Applica- tions, Springer, Boston, 2008, pp. 55-65.

[2] F. Villeneuve and F. Vignat, "Manufacturing Process Simulation for Tolerance Analysis and Synthesis," Proceedings of IDMME, 2004, Bath, 10 pages.

[3] M. H. Kyung and E. Sacks, "Nonlinear Kinematic Tolerance Analysis of Planar Mechanical Systems," Computer Aided Design, Vol. 35, No. 10, 2003, pp. 901-911.

[4] R. J. Gerth and W. M. Hancock, "Computer Aided Tolerance Analysis for Improved Process Control," Internationl Journal of Computers and Industrial Engineering, Vol. 38, No. 1, 2000, pp. 1-19.

[5] Z. Shen, G. Ameta, J. J. Shah and J. K. Davidson, "A Comparative Study of Tolerance Analysis Methods," Journal of Computing and Information Science in Engineering, Vol. 5, No. 3, 2005, pp. 274-284.

[6] J. Hu, G. Xiong and Z. Wu, "A variational Geometric Constraints Network for a Tolerance Types Specification," International Journal of Advanced Manufacture Technology, Vol. 24, No. 3-4, 2004, pp. 214-222.

[7] U. Roy and B. Li, "Representation and Interpretation of Geometric Tolerances for Polyhedral Objects," Computer Aided Design, Vol. 31, No. 4, 1999, pp. 273-285.

[8] J. Y. Dantan, J. Bruyere, J. P. Vincent and R. Bigot, "Vectorial Tolerance Allocation of Bevel Gear by Discrete Optimization," Mechanism and Machine Theory, Vol. 43, No. 11, 2008, pp. 1478-1494.

[9] E. Ballot and P. Bourdet, "A Computation Method for the Consequences of Geometric Errors in Mechanisms," Proceedings of CIRP Seminar on Computer Aided Tolerancing, Toronto, Canada, April 1997, pp. 197-207.

[10] M. Giordano, S. Samper and J. P. Petit, "Tolerance Analysis and Synthesis by Means of Deviation Domains, AxiSymmetric Cases" of the 9th CIRP International Seminar on Computer Aided Tolerancing, Tempe (US), April, 2005, pp. 85-94.

[11] A. Mujezinovic, J. K. Davidson and J. J. Shah, "A New Mathematical Model for Geometric Tolerances as Applied to Polygonal Faces," Transaction of the ASME, Journal of Mechanical Design, Vol. 126, No. 4, 2004, pp. 504-518.

[12] J. P. Petit, S. Samper and M. Giordano, "Minimum Clearance for Tolerance Analysis of a Vacuum Pump," Proceedings of the 8th CIRP seminar on computer aided design, Chalrotte (US), 2003, pp. 43-51.

[13] S. Bhide, G. Ameta, J. K. Davidson and J. J. Shah, "Tolerance-Maps Applied to the Straightness and Orientation of an Axis" of the 9th CIRP International Seminar on Computer Aided Tolerancing, Tempe (US), April 2005, pp. 45-54.

[14] Z. Zou and E. P. Morse, "A Gap-Based Approach to Capture Fitting Conditions for Mechanical Assembly," Computer Aided Design, Vol. 36, No. 8, 2004, pp. 691 -700 .

[15] J. Y. Dantan, L. Mathieu, A. Ballu and P. Martin, "Tolerance Synthesis: Quantifier Notion and Virtual Boundary," Computer Aided Design, Vol. 37, No. 2, 2005, pp. 231-240. 
[16] S. Tichadou, O. Legoff and J. Y. Hascoet, "Quantification of Machining and Fixture Errors: 3d Method and Analysis of Planar Mechanical Systems," Computer Aided Design, Vol. 35, No. 10, 2003, pp. 901-911.

[17] E. Sacks and L. Joskowicz, "Parametric Kinematic Tolerance Analysis of Planar Mechanisms," Journal of Computer Aided Design, Vol. 29, No. 5, 1997, pp. 333-342.
[18] M. Kyung and E. Sacks, "Nonlinear Kinematic Tolerance Analysis of Planar Mechanical Systems," Computer Aided Design, Vol. 35, No.10, 2003, pp. 901-911.

[19] M. Pillet, "Inertial Tolerancing," The Total Quality Magazine, Vol. 16, No. 3, 2004, pp. 202-209.

[20] R. Pauliac and A. Bellacicco, "Cours chaîne de cotes Process Angulaire,” Lycée Dorian Paris, 2007. 